\title{
EVALUATION OF GLASS IONOMER SEALANTS PLACED ACCORDING TO THE ART APPROACH IN A COMMUNITY WITH HIGH CARIES EXPERIENCE: 1-YEAR FOLLOW-UP
}

\author{
AVALIAÇÃO DE SELANTES IONOMÉRICOS REALIZADOS PELA TÉCNICA DO ART EM \\ COMUNIDADE COM ALTA EXPERIÊNCIA DE CÁRIE: 1 ANO DE ACOMPANHAMENTO
}

\begin{abstract}
Ana Luiza Falavinha VIEIRA ${ }^{1}$, Nildiceli Leite Melo ZANELLA ${ }^{1}$, Eduardo BRESCIANI ${ }^{2}$, Terezinha de Jesus Esteves BARATA ${ }^{2}$, Salete Moura Bonifácio da SILVA ${ }^{3}$, Maria Aparecida de Andrade Moreira MACHADO ${ }^{4}$, Maria Fidela de Lima NAVARRO ${ }^{5}$
\end{abstract}

\author{
1- DDS, MSc, PhD, Assistant Professor, Department of Pediatric Dentistry, Paulista University -UNIP, Brazil. \\ 2- DDS, MSc, Graduate student (Doctor degree), Department of Operative Dentistry, Endodontics and Dental Materials, Bauru Dental School, \\ University of São Paulo, Brazil. \\ 3- DDS, MSc, PhD, Assistant Professor, Department of Pediatric Dentistry, Bauru Dental School, University of São Paulo, Brazil. \\ 4- DDS, MSc, PhD, Associate Professor, Department of Pediatric Dentistry, Bauru Dental School, University of São Paulo, Brazil. \\ 5- DDS, PhD, Associate Professor, Department of Operative Dentistry, Endodontics and Dental Materials, Bauru Dental School, University of \\ São Paulo, Brazil. \\ Corresponding address: Profa. Dra. Maria Fidela de Lima Navarro - Department of Operative Dentistry, Endodontics and Dental Materials, \\ Bauru Dental School, University of São Paulo, Al Dr Otávio Pinheiro Brisola 9-75 - Bauru - São Paulo-Brazil - Cep: 17012-101 \\ Tel. 5514 3234-7688 - FAX: 551432234679 - e-mail:mflnavar@usp.br
}

Received: August 30, 2005 - Modification: February 02, 2006 - Accepted: June 14, 2006

\begin{abstract}
$T_{\text {he }}$

he aim of this study was to investigate the retention rates and effect on occlusal caries incidence of two glass ionomers used as sealants, placed according to the Atraumatic Restorative Treatment (ART) approach, in a high caries-risk community. A total of 150 newly erupted first molars of 42 schoolchildren, between 6-8 years of age were selected. The teeth were divided into two groups: experimental and control groups. In the experimental group, 76 teeth were sealed using Vidrion R-SS White (conventional GIC) and in the control group, 74 teeth were sealed using ChemFlex-Dentsply (high-viscosity conventional GIC). The sealants were applied by one operator following the "press finger technique", described in the ART-WHO manual. Two calibrated independent examiners carried out the evaluation according to the ART criteria. The intra and interexaminer agreements were 0.84 and 0.81 , respectively. Data were submitted to Mann-Whitney and Chi-square tests $(\mathrm{p}<0.05)$. At the 1 -year followup, $136(90.7 \%)$ sealants were evaluated. In the control group: 28 (41.8\%) of the sealants were partially or completely retained, 38 (56.7\%) completely lost, and $1(1.5 \%)$ was replaced by another treatment. In the experimental group, 30 (43.5\%) of the sealants were partially or completely retained, 38 (55.1\%) were clinically scored as complete loss and $1(1.4 \%)$ were replaced by another treatment. Seven sealants in both groups were not evaluated. Secondary caries was not observed in both groups. There was no statistically significant difference between the retention ( $\mathrm{p}=0.49)$ and effect on caries incidence rates for both groups $(\mathrm{p}=0.84)$. The clinical performance of the glass ionomer sealants of both groups was considered satisfactory with a high success rate (98.5\%). Although the sealants placed according to the ART approach showed retention rates lower than 50\% after 1 year in newly erupted first molars, this approach seems to be appropriate for communities with high caries experience.

Uniterms: Pit and fissure sealants; Sealants, clinical trials; Glass ionomer cements; ART, Atraumatic Restorative Treatment.
\end{abstract}

\begin{abstract}
RESUMO
objetivo deste trabalho foi avaliar o índice de retenção e o efeito na incidência de cárie oclusal de dois selantes ionoméricos realizados pela técnica do Tratamento Restaurador Atraumático (ART) em comunidades com alto índice de cárie. Foram selecionados 150 primeiros molares recémerupcionados de 42 escolares, entre 6-8 anos de idade. Os dentes foram divididos em dois grupos: experimental e controle. No grupo experimental 76 dentes foram selados com Vidrion R-SSWhite (CIV-convencional) e no grupo controle, 74 dentes foram selados com ChemFlex-Dentsply (CIV-alta viscosidade). Os selantes foram realizados por apenas um operador pela técnica da "pressão digital", descrita no manual de ART da OMS. Dois avaliadores independentes e calibrados segundo os critérios do ART realizaram a avaliação. A concordância intra e inter-examinadores foi de 0,84 e 0,81, respectivamente. Os resultados foram submetidos aos testes Mann-Whitney e Q-quadrado ( $<00,05)$. Após um ano, $136(90,7 \%)$ selante foram avaliados. No grupo controle, 28 (41,8\%) selantes estavam parcial ou completamente retidos, 38 (56,7\%) completamente perdidos, 1 (1,5\%) foi substituído por outro tratamento. No grupo experimental, 30 (43,5\%) selantes estavam parcial ou completamente retidos, 38 (55,1\%) foram classificados como completamente perdidos e $1(1,4 \%)$ foi substituído por outro tratamento. Sete selantes em ambos os grupos não foram avaliados. A presença de lesão cariosa secundária não foi observada em nenhum dos grupos. Não houve diferença estatisticamente significante entre a retenção $(p=0,49)$ e efeito na incidência de cárie $(p=0,84)$ entre os dois grupos. A performance clínica dos selantes ionoméricos foi considerada satisfatória com um alto índice de sucesso (98,5\%). Embora os selantes aplicados de acordo com a técnica ART tenham mostrado índices de retenção abaixo de 50\% depois de um ano nos primeiros molares recém-erupcionados, este método mostrou-se apropriado para comunidades com alta experiência de cárie. Unitermos: Selante de fossas e fissuras; Selantes, avaliação clínica; Cimentos de ionômero de vidro; ART; Tratamento Restaurador Atraumático.
\end{abstract}




\section{INTRODUCTION}

Occlusal surfaces of erupting molars are highly susceptible to dental decay ${ }^{4,17,22}$. This caries susceptibility period comprehends a 1.0-1.5-year-long eruption phase ${ }^{4}$. Pit and fissure alone in optimal fluoridated and nonfluoridated regions represent approximately 55 to $60 \%$ of all caries within the group from 5 to 17 year-old subjects ${ }^{12}$. Longitudinal studies of a single application of resin sealants demonstrated the remarkable effectiveness in caries prevention ${ }^{21}$, although caries still occurs in pit and fissures where the sealant was completely or partially lost ${ }^{12}$. Thus, the introduction of glass ionomer cements (GIC's) adds another possibility of pit and fissure caries prevention ${ }^{16,20,23,24}$. Mejàre and $\mathrm{Mjör}^{16}$ (1990) using a replica scoring technique recorded clinically extensive loss of $61 \%$ of the glass ionomer sealants after 6-12 months, but all occlusal surfaces sealed with this material remained cariesfree. This finding may be explained by the fact that even after the glass ionomer sealant had been clinically registered as lost, the replicas revealed areas of retained sealant remnants in 93\% after 30-36 months.

Although conventional pit and fissure sealants may prevent caries, in many developing countries, dental caries is still left untreated within the majority of the population and is the main cause of tooth extraction ${ }^{15,18}$. In fact, this group, with no access to proper oral care, constitutes at least two-thirds of the world population ${ }^{18}$. Considering this reality, a new method for treating dental caries was presented at the headquarters of the World Health Organization on World Health Day in $1994^{11}$. This approach called "Atraumatic Restorative Treatment" (ART) was introduced as a potentially viable mean of providing restorative and preventive care ${ }^{11,14}$. The ART approach uses GIC as a restorative material and as a fissure sealant in permanent and primary teeth and combines both preventive and restorative procedures ${ }^{11}$. The objective of sealing the fissures according to the ART approach is to prevent and/ or arrest fissure caries. According to the technique, glass ionomer sealants are recommended: (1) where there is fissure caries restricted to the enamel; (2) for caries-free teeth with a deep pit and fissures morphology; (3) in patients who are assessed to be of high caries-risk ${ }^{11}$.

The mean DMFT indexes of the reported studies with ART are very low, ranging from $0.6^{14}$ to $1.1^{12}$. There is a lack of information regarding ART sealants success in population with high caries experience. Therefore, the aim of this study was to evaluate the clinical performance (retention rate and the caries-preventive effect) of sealants placed according to the ART approach, comparing two glass ionomer cement restorative materials designed for ART approach in newly erupted first molars of children with high caries experience.

\section{MATERIALAND METHODS}

This study was conducted in an elementary school in a suburban area of Bauru/Brazil. The study plan was approved by the Institutional Review Board of Bauru Dental School, University of São Paulo, according to the guidelines of the Declaration of Helsink.

\section{Sample selection}

For selection, the subjects should present at least two sound and unsealed newly erupted first molar teeth. Only those students with formal written parent consent took part in this study.

The sample consisted of 150 newly erupted first molar teeth. The teeth were divided into two groups:

- Experimental group (76 teeth) - application of Vidrion RSS White, conventional glass ionomer cement. Vidrion $\mathrm{R}$ was tested in this study as sealant material, because it has been currently used in Public Oral Health Service, mainly due to its low cost and high fluoride release.

- Control group (74 teeth) - application of ChemFlexDentsply, high-viscosity conventional glass ionomer cement. ChemFlex was chosen as control material, because it is a high viscous GIC specially developed for the ART approach $^{11}$.

Each patient received at least one pair of sealants using the two different GIC. The material to be used as an occlusal sealant was chosen randomly. The specifications of the glass ionomer cements are summarized in Table 1.

\section{Clinical Procedures}

One operator previously trained and calibrated carried out all clinical procedures. The dentist was assisted by one chair-side assistant.

A baseline examination of the oral health status was conducted in all patients and the Visible Plaque Index (VPI), Gingival Bleeding Index (GBI) based on Ainamo and Bay ${ }^{1}$ in 1975, and DMFT index were assessed. To determine VPI, every tooth on the right hemi section was evaluated. Regarding the GBI, every first permanent molar, the maxillary right central incisor and the mandibular left central incisor were evaluated. In each tooth, three different areas were observed, namely two facial and one lingual surfaces. On the facial surface, the medial and central points of its cervical portion were evaluated, while on the lingual surface just a central point of its cervical portion was assessed. If visible

TABLE 1- Tested glass ionomer cements (GIC)

\begin{tabular}{|c|c|c|c|}
\hline GIC & Manufacturers & Classification & Batch \# - expiry date \\
\hline ChemFlex & Dentsply, USA & Highly viscous & $9804001577-03 / 2005$ \\
\hline Vidrion $\mathrm{R}$ & SS White, Brazil & Conventional & $03111039-09 / 2005$ \\
\hline
\end{tabular}


plaque or bleeding were observed, a score 1 was written down. Score 0 indicated no plaque or bleeding presence. When a tooth was not present in oral cavity or it was impossible to examine, a score 9 was written down and the tooth excluded from the percentage calculation. This method was chosen by its facility to be executed and to clarify patients about their oral conditions.

Sealants were applied according to the WHO-ART manual ${ }^{11}$. Patients were fit in a proper position to the operator on a table with a cushioned headrest attached for their comfort. No electrically driven equipment was used. Plaque and debris were removed from the surface to be sealed with an explorer (Duflex - SS White, Petrópolis, Brazil) and by wiping those areas with a cotton wool pellet followed by the application of polyacrylic acid solution (40\%) (Durelon - 3M ESPE, Seefeld, Germany) for 10s. Moisture control was achieved by cotton rolls. The conditioned surface was washed with cotton wool pellets and dried with dry cotton pellets before the mixture was applied. The glass ionomer was mixed according to the manufacturer's instruction and placed on the occlusal pit and fissures with the round end of the applier/carver (Duflex - SS White, Petrópolis, Brazil). The pits and fissures were slightly overfilled and in order to enhance adherence and penetration of the material, a gloved finger with petroleum jelly was used to push the material into pits and fissures. After one minute of pressure, the excess was removed and the material was covered with a surface protector: nail varnish (Colorama- Procosa Ltda., São Paulo, Brazil). After initial hardening of the material, the occlusion was checked using articulating paper (AccuFilm II - CE, Farmingdale, USA) and, if necessary, adjusted. The patients were instructed not to eat for at least one hour. All sealants were photographed at baseline and at the 1 year follow-up. All children received instructions of oral health and healthy eating habits by the chair-side assistant. Each child received toothbrush and toothpaste.

\section{Evaluation}

The clinical evaluation was carried out after 1 year by two calibrated independent double-blind examiners. The codes and criteria used to evaluate the sealants are given in Table 2. Sealants with codes 0,1 and 2 were considered success; codes 3, 4 and 5 were considered failures. Duplicate examinations were carried out on a random sample of $10 \%$

TABLE 2- Codes used in the evaluation of sealants

\begin{tabular}{ll}
\hline Codes* Criteria \\
\hline
\end{tabular}

0 Sealant completely present, no caries

$1 \quad$ Partly present, no caries

$2 \quad$ Completely lost, no caries

3 Partly present, with caries

4 Replaced by an other treatment

$5 \quad$ Lost, with caries

*Success: 0, 1 and 2; Failure: 3, 4 and 5 of the sealants.

Prior to the evaluation, visible debris and plaque were removed with an explorer. The teeth were cleaned with water on a small cotton pellet and dried using a cotton pellet. The examination site was well illuminated and the evaluation was performed using WHO periodontal probes, explorers, plane front-surface mirrors and a light source. In addition slides were taken at baseline and after 1 year of sealant insertion.

\section{STATISTICALANALYSIS}

The collected data were entered into a Microsoft Excel worksheet and analyzed using SPSS software for Windows Version 5.1 (Stat Soft Inc., Tulsa, USA).

Differences in the results between sealant groups by age, gender, type of first molar (16-26-36-46) and jaw (maxillary or mandibular) were tested using the chi-square test.

The comparison of the mean time required to carry out sealants for both groups was analyzed using Student's test. Chi-square test was employed to statistically evaluate the success rates (caries experience) between experimental (Vidrion R) and control (ChemFlex) groups. Mann-Whitney test was used to compare the differences between the retention rates in the two groups (experimental and control). A p value lower than 0.05 indicates statistical significance. Kappa test was used to verify inter and intra-examiner reproducibility for the clinical assessment regarding sealant retention and caries prevalence.

\section{RESULTS}

\section{Baseline information}

In this study, the sample was composed of 42 schoolchildren, aged 6-8 years. At baseline, regarding to GBI and to VPI, the mean values were respectively $21.3 \%+19.5$ and $54.7 \%+25.0$. The mean DMFT and dmft scores were respectively $0.9 \pm 1.4$ and $2.3 \pm 2.7$. There were no statistically significant differences between the experimental and test groups by age, gender, type of first molar and jaw at baseline (Chi-square test $=0.160, \mathrm{p}=0.688$ ).

The average time required to carry out sealants was $10.15 \pm 1.5$ minutes for experimental group and 10.2 \pm 1.7 minutes for control group. This difference was not statistically significant (Student's test, $\mathrm{p}=0.99$ ).

\section{One-year follow-up}

Results of the duplicate examinations on sealants status showed good intra-examiner reproducibility with kappa values ranging from 0.78 to 0.90 . Inter-examiner reproducibility was also good with kappa values 0.81 .

After 1 year, 38 patients (90.5\%) and 136 sealants (90.7\%) were evaluated. Due to the irregular school attendance of the children, few patients were evaluated in the first two attempts of follow-up (50\%). The related reasons were absence from school on the day of evaluation (30\%), 
transfers to another school (15\%) and diseases (5\%). Nevertheless the dropout rate in the first year of this study was considered low. Only four patients (9.5\%) were not evaluated, because they moved to other cities. One-third of all appointments were made at the patients' houses.

In relation to retention rates and caries incidence, there were no statistically significant differences between the experimental and test groups by age, gender, type of first molar and jaw at the 1-year recall (Chi-square test $=1.18$, $\mathrm{p}=0.55$ ).

Table 3 details the status of the sealants after 1 year for both experimental and control groups. Most of the sealants were partly or completely lost during the first year after placement. In addition, only $5.8 \%$ and $13.4 \%$ of sealants were completely retained for the experimental and control groups, respectively. Replacement by other treatment was found in only 1 tooth in each group. There was no statistically significant difference in the retention of sealants between experimental and control groups (Mann-Whitney test $=227.5$, $\mathrm{p}=0.84$ )

There was no statistically significant difference in the success rates (caries incidence) after 1 year between experimental (Vidrion R) and control (ChemFlex) groups. (Chisquare test $=0.478, \mathrm{p}=0.49)$. None of the sealed teeth developed caries in the first year of evaluation.

\section{DISCUSSION}

The 1-year lost-to-follow-up rate was lower (9.5\%) than a similar study $(28.6 \%)^{10}$. According to Chadwick, et al. ${ }^{6}$ (2005), the main reason that children could not be evaluated was due to children moving to other parts of the city, to rural areas or to others cities. Thus, in this study, particular attention was given to the patient chart information and also to the public school record system. The chart included the parents and friends' addresses and phone numbers. In case the patient could not be found by the information in the chart, the previous public school could find the patient's new school if still inside the State. These efforts resulted in

TABLE 3- Status of the sealants after 1 year

\begin{tabular}{lllll} 
Codes* $^{*}$ & \multicolumn{3}{c}{ Groups } \\
& $\begin{array}{l}\text { Experimental } \\
\text { Vidrion } \\
(\mathrm{n}=76)\end{array}$ & \multicolumn{2}{l}{$\begin{array}{l}\text { Control } \\
\text { ChemFlex } \\
(\mathrm{n}=74)\end{array}$} \\
& $\mathrm{n}$ & $\%$ & $\mathrm{n}$ & $\%$ \\
& 4 & 5.8 & 9 & 13.4 \\
0 & 26 & 37.7 & 19 & 28.4 \\
1 & 38 & 55.1 & 38 & 56.7 \\
2 & 1 & 1.4 & 1 & 1.5 \\
4 & 69 & 100 & 67 & 100 \\
TOTAL & 1 & & & \\
\hline
\end{tabular}

*Success: 0, 1 and 2; Failure: 3, 4 and 5 a lower dropout. However, it should be pointed out that few patients had been seen in the first two appointments. The main reasons for that observation were transfers to other schools, absence at the day of examination and health problems. Three appointments were required in the average to complete the evaluation and one-third of all appointments were made in the patients' houses. At the end, fourteen sealants within four children were not evaluated because they moved. However, this does not jeopardize the conclusions of the present study, and the lost to follow-up was similar to that obtained by Beirute, et al. ${ }^{3}$ (2006).

The "press-finger" technique is recommended for sealants placed according to the ART approach ${ }^{11}$. This technique condenses and ensures penetration of the cement into the pits and fissures ${ }^{11}$. Fracasso, et al. ${ }^{7}$ (2005), observed that the sealants tested (Delton, Ketac-Molar, Fuji Plus, Vitremer) presented a similar pattern of penetration into the pits and fissures, with no statistically significant difference among the studied groups. The high viscosity GIC's can be compensated by the finger pressure technique, as indicated in the ART approach ${ }^{11}$. In the present study, the "pressfinger" technique was also performed.

Comparing the performance of the two GIC's used in this study, there were no differences between them in relation to retention and caries incidence, although ChemFlex is a high-viscosity GIC's and Vidrion R, a conventional one. These results should be faced in a positive manner because the conventional GIC's (Vidrion R) is a Brazilian marketed material. It is less expensive and presents better cost/benefit for sealant application. The majority of the sealants were clinically assessed as completely lost during the $1^{\text {st }}$ year after placement, being $55.1 \%$ and $56.7 \%$ in the experimental (Vidrion R) and control (ChemFlex) groups, respectively. This observed difference was no statistically significant between the groups.

Despite of the high loss observed, the GIC sealants seemed to play their hole, preventing the incidence of occlusal caries in both groups, similarly to other studies ${ }^{16,17}$. There were no caries observed in the two tested groups after one year. Two teeth, one in each group received amalgam restoration and they were scored as failure supposing caries was present and the teeth were restored before the evaluation period. The presence of caries-free sealed teeth was $98.5 \%$.

Comparing to other similar studies ${ }^{8,10}$, the present one shows lower retention rates. This fact may be related to several reasons: the age of the treated children, newly erupted teeth and pit and fissure anatomy. In other previous studies where higher retention rates were observed, the mean age of the subjects was between 13 to 14 years. At this age the patients seem to be more cooperative and the treatment itself is more easily performed, and thus the retention rate may be higher. Another difference among this and other studies is the fact that the sealants were performed in newly erupted molars, which makes moisture control harder to achieve. Another possible reason for the low retention rates is that the sealed teeth did not present deep and narrow pit and fissures. 
In relation to the retention rates and the caries-incidence, there were no statistically significant differences between the experimental and test groups by gender, type of first molar and jaw at the 1 year recall. This result observed was comparable to those presented in literature ${ }^{3,5,13,14,19}$, probably due to standardization of procedures.

The main reason for occlusal sealant placement is to prevent caries. In this study, the sealants, regardless of their retention levels, showed to be beneficial. The caries-free teeth after 1 year were $98.5 \%$ for both tested groups and it is in accordance with other studies that presented rates of caries-free teeth varying from $96.1 \%$ to $100 \%$ after one year ${ }^{3,8-}$ $10,13,14,17$.

Furthermore GIC's sealants, according to the ART approach, appear to have a four times higher chance of preventing caries development in re-exposed pits and fissures of occlusal surfaces in first molars compared to light-cured composite resin sealant material over a 1- to 3year period ${ }^{3}$.

It is interesting to note, in this study, that sealing newly erupted first molars with GIC's may be a caries-preventive measure in high-risk children. The probable reason for this observation is that the GIC sealants even being clinically lost, still remain on the bottom of the fissure, protecting the tooth from occlusal caries development ${ }^{2,16,17,20,23}$.

ART studies report an operator effect on the success of treatment ${ }^{8-10,13,14}$. In those studies, the outcomes revealed that less experienced operators obtain worse results compared to experienced ones ${ }^{8-10,13,14}$. In the present study, only one operator previously trained and calibrated assisted by one chair-side assistant placed all sealants.

The average time required to place sealants (10.15 to10.2 minutes) was in line with the time required in ART studies (8.2 to 10.8 minutes) $)^{9,10,13,14}$. In ART studies ${ }^{9,10,13,14}$ the average time is higher than when sealants are applied in a conventional way, probably because the occlusal surface is cleaned without utilization of rotary instruments, only with manual cleaning of the pits and fissures.

Since ART approach is not dependent upon expensive and sophisticated dental equipment, the adoption of this approach in outreaching dental programs in school environment will help to improve the young population access to dental care and caries prevention. Thus, the oral health services in Brazil can be improved using cariespreventive measures such as GIC's sealants, tooth cleaning with a fluoride toothpaste and dietary control that are long lasting and, therefore, potentially cost-effective.

\section{CONCLUSIONS}

Although the sealants placed according to the ART approach showed low retention rates in newly erupted first molars, they were efficient in keeping the studied teeth free of caries after a period of one year in children with high caries experience.

\section{REFERENCES}

1- Ainamo J, Bay I. Problems and proposals for recording gingivitis and plaque. Int Dent J. 1975;25:229-35.

2- Antonson SA, Wanuck J, Antonson DE. Surface protection for newly erupting first molars. Compend Contin Educ Dent. 2006;27:4652.

3- Beiruti N, Frencken JE, van’t Hof MA, Taifour D, van PalensteinHelderman WH. Caries-preventive effect of a one-time application of composite resin and glass ionomer sealants after 5 years. Caries Res. 2006;40:52-9.

4- Carvalho JC, Thylstrup A, Ekstrand KR. Results after 3 years of non-operative occlusal caries treatment of erupting permanent first molars. Community Dent Oral Epidemiol. 1992;20:187-92.

5- Chadwick BL, Treasure ET, Playle RA. A randomised controlled trial to determine the effectiveness of glass ionomer sealants in preschool children. Caries Res. 2005;39:34-40.

6- Chadwick BL, Treasure ET. Primary care research: difficulties recruiting preschool children to clinical trials. Int J Paediatr Dent. 2005;15:197-204.

7- Fracasso MLC, Rios D; Machado MAAM, da Silva SMB, Abdo RCC. Avaliação da microinfiltração marginal e profundidade de penetração dos cimentos de ionômero de vidro utilizados como selantes oclusais. J Appl Oral Sci. 2005;13:269-74.

8- Frencken JE, Makoni F, Sithole WD, Hackenitz E. Three-year survival of one-surface ART restorations and glass-ionomer sealants in a school oral health programme in Zimbabwe. Caries Res. 1998;32:119-26.

9- Frencken JE, Makoni F, Sithole WD. ART restorations and glassionomer sealants in Zimbabwe: survival after 3 years. Community Dent Oral Epidemiol 1998;26:372-81.

10- Frencken JE, Makoni F, Sithole WD. Atraumatic restorative treatment and glass-ionomer sealants in a school oral health programme in Zimbabwe: evaluation after 1 year. Caries Res. 1996;30:428-33.

11- Frencken JE, Phantumvanit P, Pilot T, Songpaisan Y, van Amerogen E. Manual for the Atraumatic Restorative Treatment Approach to control Dental Caries. $3^{\mathrm{a}} \mathrm{ed}$, WHO Collaborating Centre for Oral Health Services Research, Groningen; 1997.

12- Hicks MJ, Flaitz CM, Garcia-Godoy F. Fluoride-releasing sealant and caries-like enamel lesion formation in vitro. J Clin Pediatr Dent. 2000;24:215-9.

13- Ho TF, Smales RJ, Fang DT. A 2-year clinical study of two glass ionomer cements used in the atraumatic restorative treatment (ART) technique. Community Dent Oral Epidemiol. 1999;27:195-201.

14- Holmgren CJ, Lo EC, Hu D, Wan H. ART restorations and sealants placed in Chinese school children - results after three years. Community Dent Oral Epidemiol. 2000;28:314-20.

15- Jovino-Silveira RC, Caldas Ade F Jr, de Souza EH, Gusmão ES. Primary reason for tooth extraction in a Brazilian adult population. Oral Health Prev Dent. 2005;3:151-7.

16- Méjare I, Mjör IA. Glass ionomer and resin-based fissure sealants: a clinical study. Scand J Dent Res. 1990;98:345-50.

17- Motsei SM, Kroon J, Holtshousen WSJ. Evaluation of atraumatic restorative treatment restorations and sealants under field conditions. SADJ. 2001;56:309-15. 
18- Pilot T. Introduction-ART from a global perspective. Community Dent Oral Epidemiol 1999; 27:421-2.

19- Poulsen S, Laurberg L, Vaeth M, Jensen U, Haubek D. A field trial of resin-based and glass-ionomer fissure sealants: clinical and radiographic assessment of caries. Community Dent Oral Epidemiol. 2006;34:36-40.

20- Seppä L, Forss H. Resistance of occlusal fissures to demineralization after loss of glass ionomer sealants in vitro. Pediatr Dent. 1991;13: 39-42.

21- Simonsen RJ. Retention and effectiveness of dental sealants after 15 years. J Am Dent Assoc. 1991;122: 34-42.

22- Taifour D, Frencken JE, van't Hof MA, Beiruti N, Truin GJ. Effects of glass ionomer sealants in newly erupted first molars after 5 years: a pilot study. Community Dent Oral Epidemiol. 2003;31:3149 .

23- Torppa-Saarinen E, Seppä L. Short-term retention of glassionomer fissure sealants. Proc Finn Dent Soc. 1990;86:83-8.

24- Uribe S. Sealants recommended to prevent caries. Evid Based Dent. 2004;5:93-4. 